\title{
Synthesis, Properties, and Humidity Resistance Enhancement of Biodegradable Cellulose-Containing Superabsorbent Polymer
}

\author{
Hongliang Guan, Junbo Li, Biyu Zhang, and Xunmin Yu \\ School of Chemistry and Environmental Engineering, Wuhan Institute of Technology, Wuhan 430074, China \\ Correspondence should be addressed to Junbo Li; jbliwit@163.com
}

Received 19 August 2016; Revised 12 October 2016; Accepted 14 December 2016; Published 10 January 2017

Academic Editor: Dirk Kuckling

Copyright ( 2017 Hongliang Guan et al. This is an open access article distributed under the Creative Commons Attribution License, which permits unrestricted use, distribution, and reproduction in any medium, provided the original work is properly cited.

To improve the humidity resistance and water absorption capacity of the superabsorbent polymer (SAP), a biodegradable cellulosecontaining polymer was successfully assembled through inverse suspension polymerization, using cellulose, acrylic acid, and acrylamide as monomers, Span-80 as dispersant, and potassium persulfate as initiator. The impact of conditions such as reaction temperature, ratio of oil to water, degree of neutralization, amount of cellulose, and cross-linking agents on the properties of the polymer were evaluated. The results showed that the as-prepared superabsorbent polymer exhibited the best water $(859 \mathrm{~g} / \mathrm{g})$ and salt water $(72.48 \mathrm{~g} / \mathrm{g})$ absorption rate, when the reaction temperature was $70^{\circ} \mathrm{C}$, monomer ratio was $1: 10$, neutralization degree was $75 \%$, and oil-water ratio was $3: 1$. Moreover, the humidity resistance of the polymer could be enhanced significantly by adding different cross-linking reagents such as epoxy chloropropane or diethylene glycol.

\section{Introduction}

Superabsorbent polymer with strong hydrophilic groups such as carboxyl and hydroxy can absorb water hundreds of times more than its own weight in a short time and exhibit good water retention even at high temperature and pressure [1-4]. The superabsorbent polymer is superior to other absorbing materials $[5,6]$. It has been widely used in many fields such as diapers, sanitary napkins, oilfield chemistry, and water soluble coatings [7-10].

The main synthesized methods for the superabsorbent polymer include bulk polymerization, solution polymerization, inverse emulsion polymerization, and inverse suspension polymerization. Zhang et al. [11] synthesized the starch graft superabsorbent polymer with larger water absorption capacity through radical polymerization in aqueous solution. Changchaivong and Khaodhiar [12] prepared a series of resins using different kinds of monomer by inverse suspension polymerization, and the water absorption rate reached $730 \mathrm{~g} / \mathrm{g}$. Mahdavinia et al. [13] synthesized superabsorbent polymer of chitosan-graft-acrylamide, and the $\mathrm{pH}$ dependence and swelling property have been fully investigated.
The superabsorbent polymer based on cellulose has the advantages of high gel strength, low soluble component content, strong water retention ability, being biodegradable, and high enzymolysis resistance [14]. Essawy et al. [15] obtained the acrylic acid and chitosan-cellulose hybrid superabsorbent hydrogels via graft polymerization. Fekete et al. [16] prepared superabsorbent hydrogels from aqueous solutions of four cellulose derivatives; the swelling properties of CMC gels with lower water uptake showed lower sensitivity to the ionic strength of the solvent. Montesano et al. [17] evaluated a novel class of cellulose-based superabsorbent hydrogels for agricultural use; the soil moisture at field capacity increased with the highest hydrogel percentage up to $400 \%$ compared to the nonamended soil. The as-prepared cellulose-based superabsorbent hydrogels showed to be suitable for potential use in agriculture. Mohammadi-Khoo et al. [18] synthesized a cellulose-based biodegradable hydrogel, which exhibited excellent swelling behavior in distilled water, tap water, and $0.9 \% \mathrm{NaCl}$ solution; it can be employed as a suitable moistureholding additive in the soil for agricultural purposes.

However, it was easy for the reported cellulose-based superabsorbent polymers to absorb moisture, which will 
seriously affect their translation, storage, and usage [19]. Thus, methods to improve the moisture-proof of resins are highly desirable. In this paper, the superabsorbent polymer with high water absorbency and gel strength was prepared under optimum conditions. The ratio of oil to water, the degree of neutralization, the amount of cellulose, and crosslinking agents on the absorption of water were investigated. Furthermore, the moisture-proof ability of the resins after modification by different kinds of cross-linking agents was also discussed carefully.

\section{Experimental}

2.1. Materials. Carboxymethyl cellulose (CMC, chemically pure, TianJin Fucheng Chemical Reagent Factory), cyclohexane (analytical grade, TianJin Fucheng Chemical Reagent Factory), potassium persulfate (analytical grade, Shanghai Kaibo Chemical Reagent Factory), N, N'-methylenebisacrylamide (analytical grade, Shanghai Kaibo Chemical Reagent Factory), sodium hydroxide (analytical grade, Shanghai Kaibo Chemical Reagent Factory), Span-80 (analytical grade, Shanghai Kaibo Chemical Reagent Factory), anhydrous ethanol (analytical grade, Shanghai Kaibo Chemical Reagent Factory), diethylene glycol (analytical grade, TianJin Fucheng Chemical Reagent Factory), epoxy chloropropane (analytical grade, TianJin Fucheng Chemical Reagent Factory), ethylene glycol (analytical grade, TianJin Fucheng Chemical Reagent Factory), polyethylene glycol (analytical grade, TianJin Fucheng Chemical Reagent Factory), ethylenediamine (analytical grade, TianJin Fucheng Chemical Reagent Factory), acrylamide (analytical grade, TianJin Fucheng Chemical Reagent Factory), and acrylic acid (analytical grade, TianJin Fucheng Chemical Reagent Factory) were distilled under reduced pressure before use.

2.2. Synthesis of Superabsorbent Polymer. A certain amount of cellulose, cyclohexane (100 g), acrylic acid (17.3 g), and acrylamide $(2.98 \mathrm{~g}$ ) was added to a four-neck flask equipped with gas line, mechanical stirrer, condenser, and thermometer and stirred at $45^{\circ} \mathrm{C}$ for $0.5 \mathrm{~h}$ under nitrogen. After the acrylic acid solution was neutralized by sodium hydroxide aqueous solution, the initiating agent potassium persulfate (KPS, $0.08 \mathrm{~g}$ ) and the cross-linking agent $\mathrm{N}, \mathrm{N}^{\prime}$-methylenebisacrylamide (MBA, $0.08 \mathrm{~g}$ ) were added to the mixture. Then, the system temperature was raised to $75^{\circ} \mathrm{C}$, and a polymeric gel was formed. Finally, the product was washed several times with ethanol and dried in vacuum at $100^{\circ} \mathrm{C}$ for $10 \mathrm{~h}$. The white powdered superabsorbent polymer was obtained by smashing.

2.3. Infrared Spectrum. Fourier Transform Infrared Spectroscopy (IR) was measured with $\mathrm{KBr}$ direct compression, scanning for 5 times at the range of $4000-400 \mathrm{~cm}^{-1}$.

2.4. Measurement of Water and Salt Water Absorbency. The dried powdered resin $(0.1 \mathrm{~g})$ was immersed in $500 \mathrm{~mL}$ distilled water and $0.9 \%$ physiological saline solution, respectively. The water-swollen gel was filtered by a sieve after

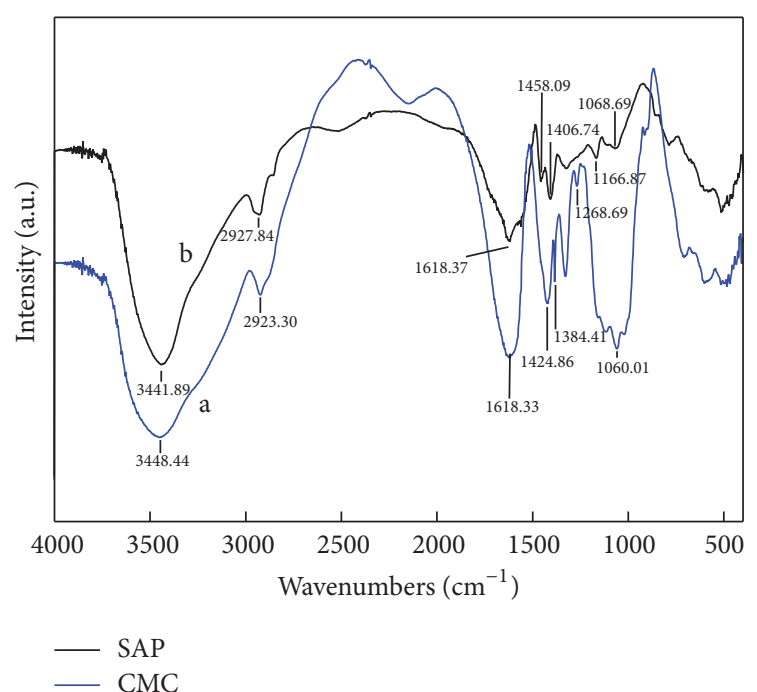

FIGURE 1: The IR spectra of CMC and the superabsorbent polymer (SAP).

soaking overnight and then weighted. The water-holding capacity was calculated by the following equation:

$$
Q=\frac{\left(M_{2}-M_{1}\right)}{M_{1}},
$$

where $M_{2}$ is the weight of water-swollen gel, $M_{1}$ is the weight of dried sample, and $Q$ is the water absorbing capacity.

2.5. Experiment for the Moisture Resistance. A certain amount of resin was divided into several groups at random and tiled on the surface of watch glass at $25^{\circ} \mathrm{C}$ with humidity of $70 \%$. The hygroscopic rate was measured and the curve was made at different times until the absorption reached saturation. Moreover, the results were compared with those of the untreated resin at the same conditions.

\section{Results and Discussion}

3.1. Infrared Spectrum Analysis. Figure 1 shows the IR spectra of CMC and SAP. The peak at $3448.44 \mathrm{~cm}^{-1}$ is the stretching vibration peak of -OH group. The peaks at $2923.30 \mathrm{~cm}^{-1}$ and $1618.33 \mathrm{~cm}^{-1}$ are attributed to $\mathrm{C}-\mathrm{H}$ symmetrical stretching vibration peak and $\mathrm{C}=\mathrm{O}$ stretching vibration peak, respectively. Compared with the IR spectrum of CMC (Figure 1(a)), the peaks at $1406.74 \mathrm{~cm}^{-1}$ and $1458.09 \mathrm{~cm}^{-1}$ (Figure $1(\mathrm{~b})$ ) are due to the $\mathrm{O}=\mathrm{C}=\mathrm{O}$ and $-\mathrm{CH}_{2}-$ in-plane bending vibration, which are the characteristic adsorption bands of sodium polyacrylate [15]. The peak at $1166.87 \mathrm{~cm}^{-1}$ is the $=\mathrm{C}-\mathrm{O}$ stretching vibration of $=\mathrm{C}-\mathrm{O}-\mathrm{C}$ and the peak at $1068.69 \mathrm{~cm}^{-1}$ is $-\mathrm{C}-\mathrm{O}$ stretching vibration of $\mathrm{C}-\mathrm{O}-\mathrm{C}$, which indicated that $\mathrm{CMC}$ was successfully grafted in SAP.

3.2. Effect of the Amount of Cellulose on the Absorption Properties of SAP. Figures 2 and 3 show the effect of the amount of cellulose on water and salt water absorption. When the monomer ratio was less than $1: 10$, the water and 


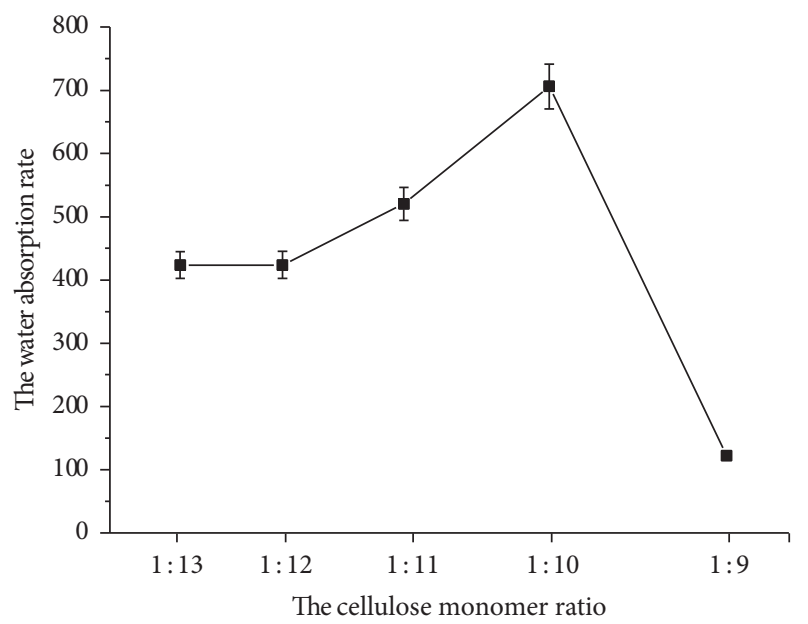

FigURE 2: Effect of the amount of cellulose on water absorption of superabsorbent polymer.

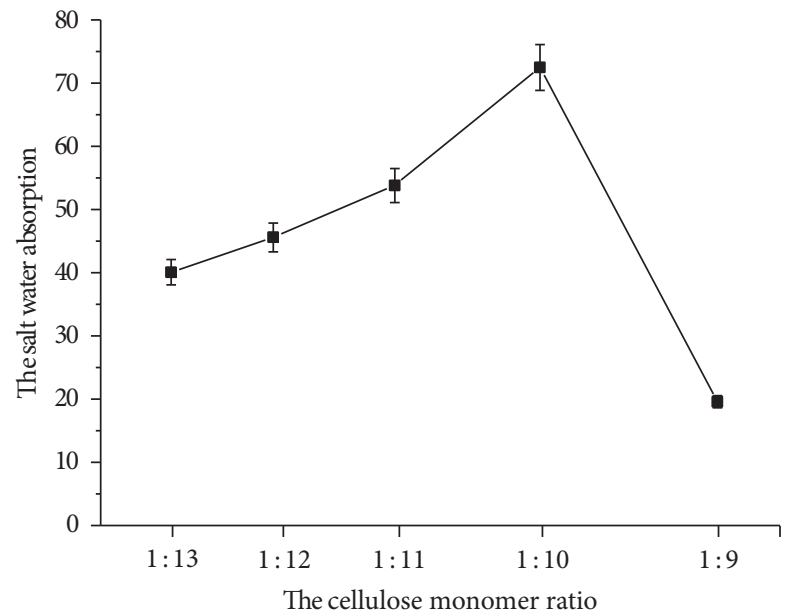

FIGURE 3: Effect of the amount of cellulose on salt water absorption of superabsorbent polymer.

salt water absorption rate significantly increased with the increasing ratio of the monomer. The maximum absorption rate for water and salt water reached $706.14 \mathrm{~g} / \mathrm{g}$ and $72.48 \mathrm{~g} / \mathrm{g}$, respectively. However, when the monomer ratio exceeded $1: 10$, the absorption rate of SAP for water and salt water decreased with the ratio increase. The results showed that the optimized monomer ratio for the absorption of water and salt water was 1:10. The possible reason is that, with the monomer ratio increase, the viscosity of the reaction system increased. It weakened the probability of the active collision between monomers and shortened polyacrylic acid acrylamide graft chains, which is adverse to the formation of polymer network structure [20-24]. On the other hand, the amount of cellulose is important for the graft polymerization and too little amount of cellulose has an adverse influence on the graft polymerization.

3.3. The Effect of Neutralization Degree on the Absorption Properties of SAP. As shown in Figures 4 and 5, the optimum neutralization degree is $75 \%$. The possible reason is as follows:

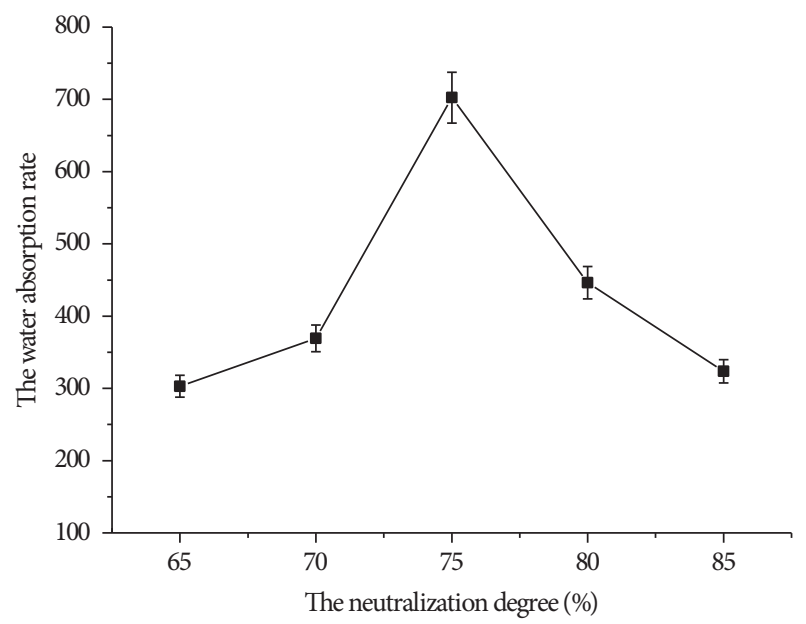

FIgURE 4: The effect of neutralization degree on water absorption of superabsorbent polymer.

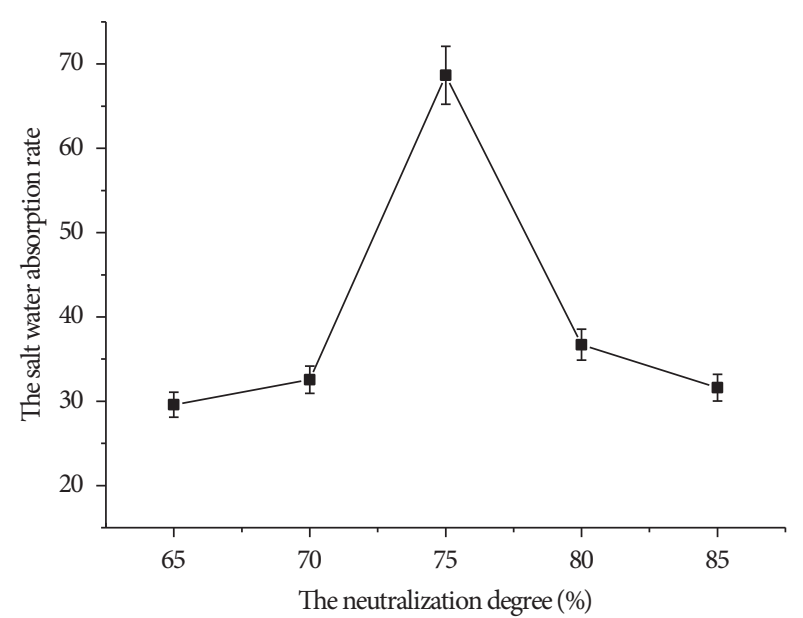

FIGURE 5: Effect of neutralization degree on salt water absorption of superabsorbent polymer.

the acidity of the solution increases with the decreasing of neutralization degree, which can accelerate the polymerization. With the increasing of neutralization process, the ionization of the carboxyl groups on the molecular chain increased [25]. Thus, the repulsive force of carboxyl groups is enhanced, which makes the molecular chain become more straight and the network structure become larger. On the other hand, the enhancement of affinity and osmotic pressure make the water and salt water absorption rate increase. Furthermore, the ion concentration becomes higher and the hydrogen bond between the water molecule and ion becomes stronger under the neutralization degree larger than $75 \%$, which limits the freedom of the molecular diffusion and makes the microporous polymer play insufficient role in the water and salt water storage [20].

3.4. Effect of Oil-Water Ratio on the Absorption Properties of SAP. As shown in Figures 6 and 7, with the increase of the oil-water proportion, the water absorption rate of the resin took on the trend with increasing firstly and decreasing 


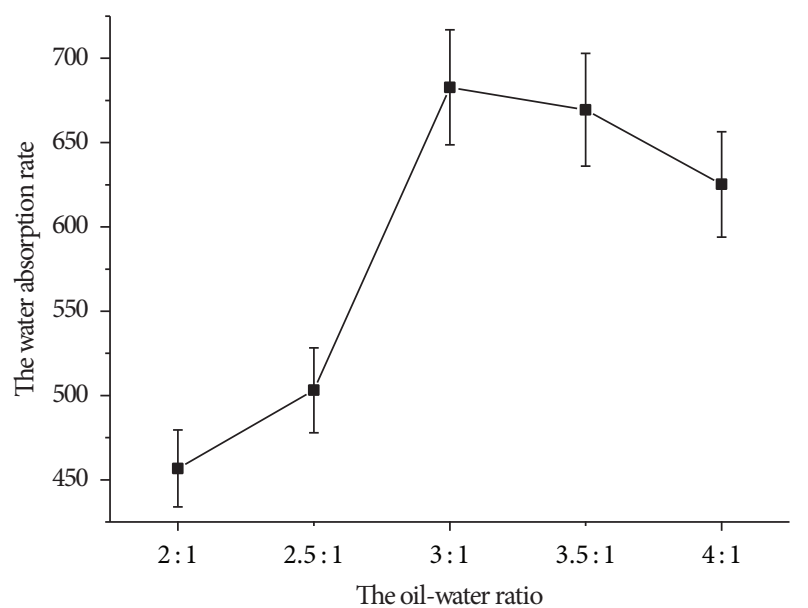

Figure 6: Effect of oil-water ratio on the water absorption of superabsorbent polymer.

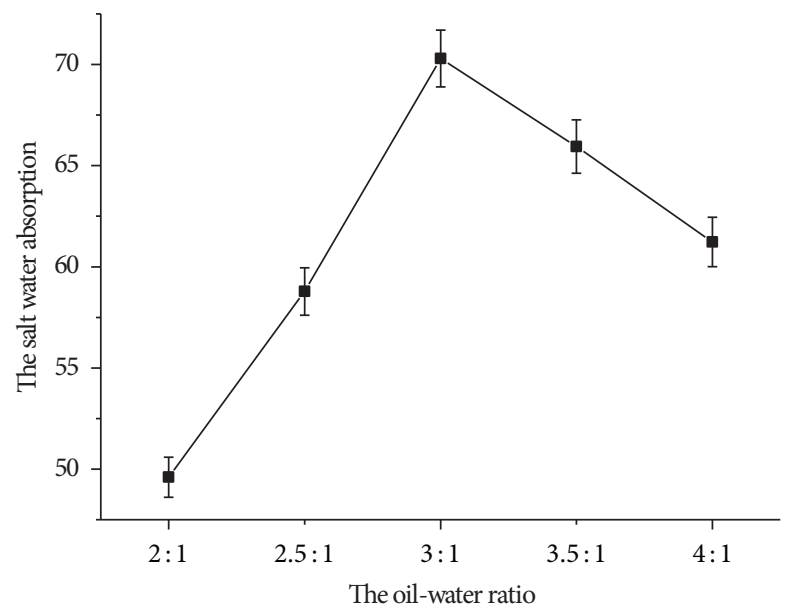

FIGURE 7: Effect of oil-water ratio on the salt water absorption of superabsorbent polymer.

afterwards. The optimum proportion of oil-water ratio was $3: 1$. When the ratio was higher than $3: 1$, the water and salt water absorption decreased obviously. This is because the acrylic acid superabsorbent resin contains a large number of hydrophilic groups, which make the SAP fully swelling in water. Actually, the ratio of oil to water has larger influence on the elasticity of hydrophilic groups (such as carboxyl and amino groups), and then it controls the swelling degree of copolymers. When the oil-water ratio is relatively high, the water in the aqueous phase can be dispersed into small droplets, and the water content in the monomer drops is low, which induces the polymer difficult to be crossed. Accordingly, the water absorption capacity decreased. When the ratio of oil to water is low, the water content in the monomer drops increased, the resin macromolecular chain could be fully extended, the cross-linking degree increased, and the water absorption rate decreased too [21].

3.5. Effect of Reaction Temperature on Absorption Properties of SAP. Figures 8 and 9 show the effect of reaction temperature on the absorption of water and salt water. Absolutely,

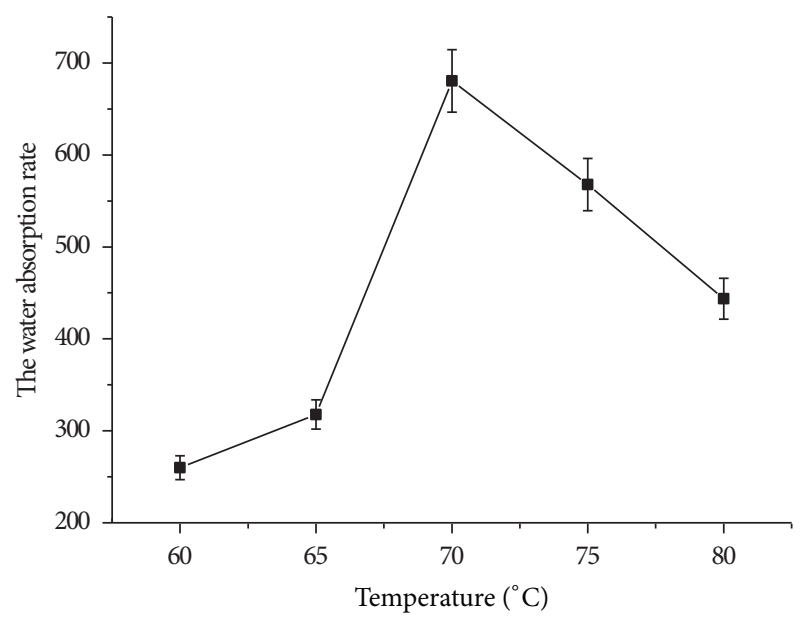

FIgURE 8: Effect of the temperature on the water absorption of superabsorbent polymer.

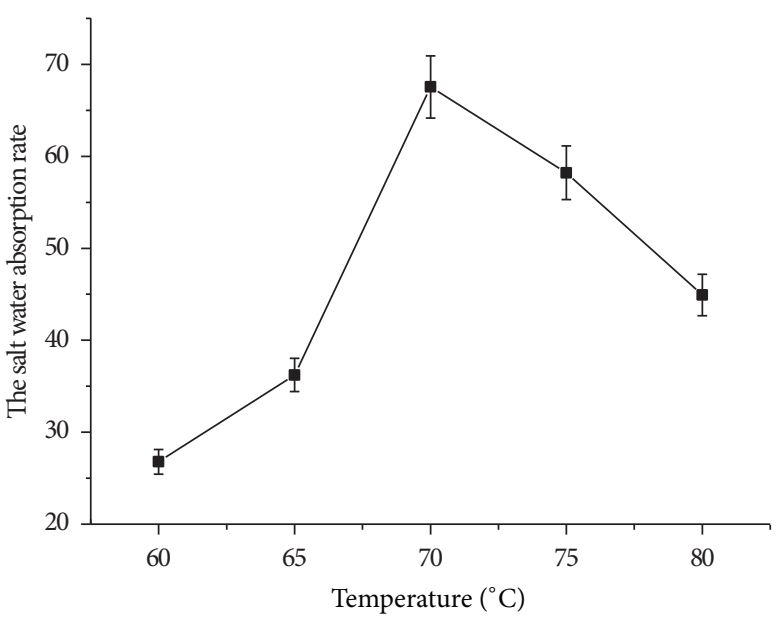

FIGURE 9: Effect of the temperature on the salt water absorption of superabsorbent polymer.

the optimum reaction temperature is $70^{\circ} \mathrm{C}$. Since the low reaction temperature reduces the activity of radical, slows down the decomposition rate of initiator agent, decreases the concentration of radical, and impedes the delivery of polymerization reaction chain, the prepared SAP with low reaction temperature shows relatively low molecular weight and water absorbency. As the reaction temperature increased, the concentration of radical increased, the conversion ratio of monomer raised, and the ability for the absorption of water and salt water increased. However, the heat is difficult to dissipate under the higher reaction temperature, explosive polymerization easily occurred, and gel disks would form.

3.6. Effect of Different Kinds of Cross-Linking Agent on the Properties of SAP. Table 1 shows the properties of SAP modified by different kinds of cross-linking agents. The results showed that the strength and dispersity of the as-prepared SAP can be improved with the addition of cross-linking reagent; however, the water absorption capacity decreased. 
TABLE 1: The absorption of SAP after modification by different surface cross-linking reagents.

\begin{tabular}{|c|c|c|c|c|}
\hline Types of cross-linking agents & Water absorption rate $(\mathrm{g} / \mathrm{g})$ & Moisture absorption (humidity resistance) & Gel strength & Dispersion \\
\hline Blank & 903 & Easy & Low and viscous & Poor \\
\hline Ethylene glycol & 861 & Easy & High, viscous & Better \\
\hline Diethylene glycol & 859 & Poor & High, relatively dry & Better \\
\hline Epoxy chloropropane $(\mathrm{ECH})$ & 832 & Poor & High, dry & Good \\
\hline Ethylenediamine & 878 & Easy & High, viscous & Better \\
\hline Polyethylene glycol & 856 & Easy & High, viscous & Poor \\
\hline
\end{tabular}

TABLE 2: Effect of epoxy chloropropane dosage on the water absorption.

\begin{tabular}{|c|c|c|c|c|c|c|}
\hline Epoxy chloropropane dosage & 0 & $5 \%$ & $10 \%$ & $15 \%$ & $20 \%$ & $25 \%$ \\
\hline Water absorption $(\mathrm{g} / \mathrm{g})$ & 902 & 883 & 859 & 835 & 794 & 782 \\
\hline
\end{tabular}

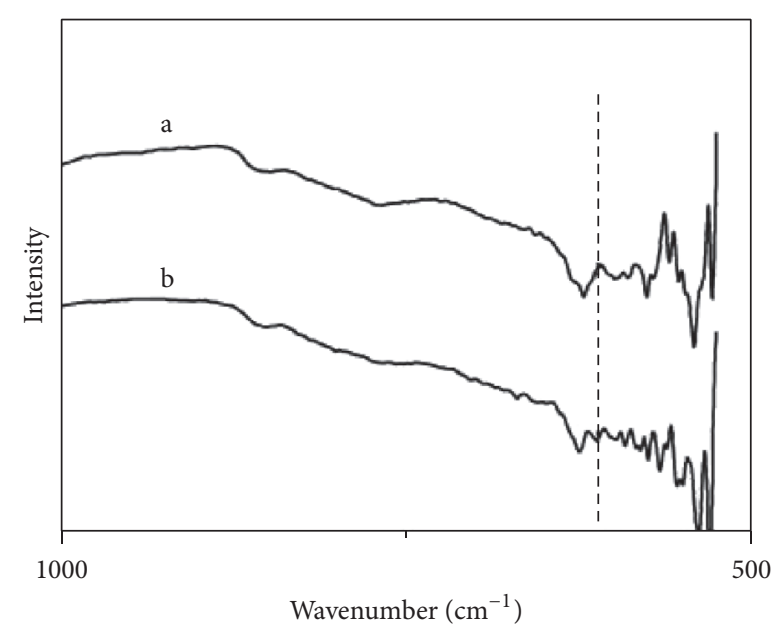

FIGURE 10: The IR comparison of the SAP before and after ECH modification (a: the IR of the SAP before ECH modification; b: the IR of the SAP modified by ECH).

The possible reason is as follows: with the addition of crosslinking reagents in the SAP, a coat on the surface of SAP may be formed through the reaction between the cross-linking agents and hydrophilic groups on the resin. Fortunately, the moisture resistance property of superabsorbent polymer was obviously enhanced when the resin was treated by epoxy chloropropane and diethylene glycol.

3.6.1. Effect of Epoxy Chloropropane (ECH) Dosages on the Properties of SAP. Figure 10 shows the spectrum of the SAP before and after ECH modification. The peak at $610-630 \mathrm{~cm}^{-1}$ is the stretching vibration peak of $\mathrm{C}-\mathrm{Cl}$, which indicated that epoxy chloropropane was successfully grafted in SAP.

Effect of Epoxy Chloropropane Dosages on the Water Absorption Properties of SAP. Table 2 shows the results of the water absorption for the different epoxy chloropropane dosages. The water absorption was tested at different mass ratios of $\mathrm{ECH}$ and $\mathrm{C}_{2} \mathrm{H}_{5} \mathrm{OH}\left(\mathrm{ECH} / \mathrm{C}_{2} \mathrm{H}_{5} \mathrm{OH}=5 \%, 10 \%\right.$, $15 \%, 20 \%, 25 \%)$, and water absorption of the resin significantly decreased with an increasing amount of epoxy chloropropane. The possible reasons are as follows: With

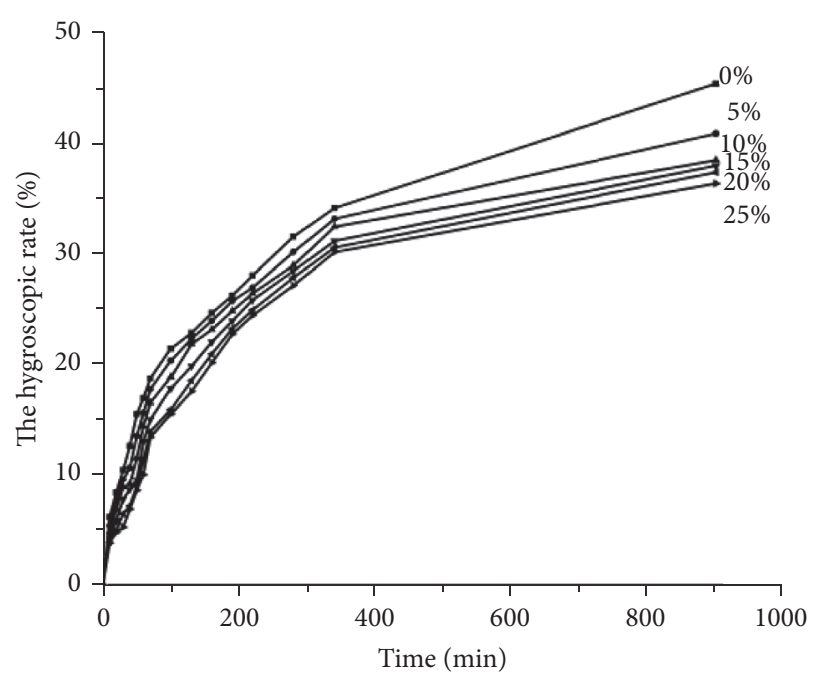

FIGURE 11: Effect of epoxy chloropropane dosages on the moisture performance of SAP.

the increasing of epoxy chloropropane dosage, the crosslinking sites, strength, and density of the SAP increased, while the molecular weight between net structure site and liquid capacity of SAP decreased.

Effect of Epoxy Chloropropane Dosages on the Moisture Resistance of SAP. Figure 11 shows the hydroscopicity of SAP with different dosages of epoxy chloropropane. To improve the moisture resistance of SAP, the surface particles of the resin were treated by thermal cross-linking to produce a high crosslinking degree coat. The SAP was modified by the mixture of $2 \mathrm{~mL}$ distilled water, $5 \mathrm{~mL}$ ethanol, and different amount of epoxy chloropropane. The results showed that, with the increasing amount of epoxy chloropropane, the moisture resistance was improved obviously. But when the amount was more than $20 \%$, the moisture resistance was no longer significantly increased.

Effect of Distilled Water Quantity on the Moisture Resistance of SAP. Absolute ethanol was used as hydrophilic solution in the process of thermal cross-linking of the resin. It was found that the effect of the absolute ethanol on the moisture resistance of SAP was not very good, when it was used as solvent. The 
TABLE 3: Effect of diethylene glycol dosages on the water absorption.

\begin{tabular}{|c|c|c|c|c|c|c|}
\hline Diethylene glycol dosage & 0 & $1 \%$ & $3 \%$ & $5 \%$ & $7 \%$ & $10 \%$ \\
\hline Water absorption $(\mathrm{g} / \mathrm{g})$ & 902 & 894 & 871 & 856 & 833 & 782 \\
\hline
\end{tabular}

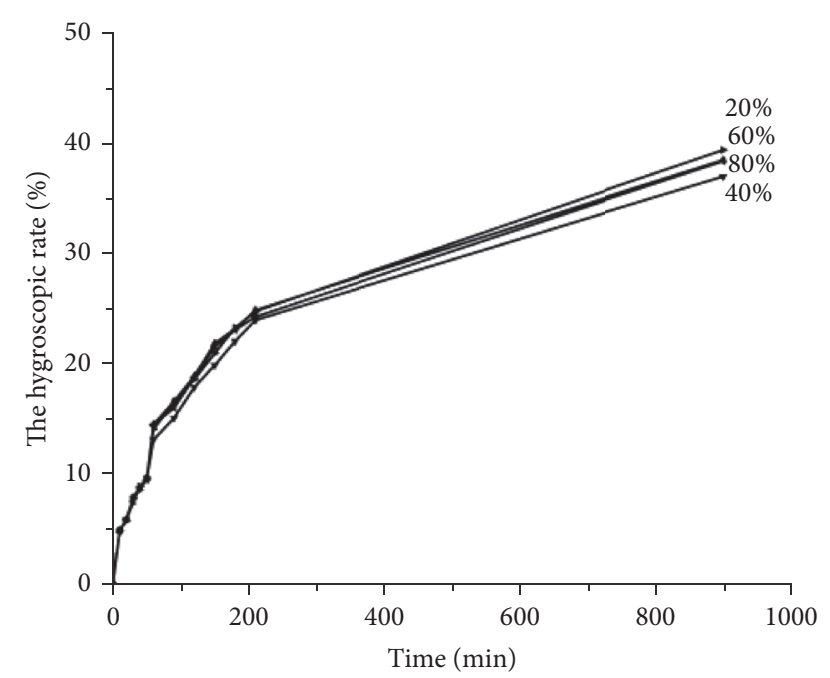

FIGURE 12: Effect of distilled water quantity on the moisture performance of SAP.

cross-linking agent only reacted with a spot of free hydroxyl groups on the surface of the resin and remaining crosslinking agents vaporized on heating. So the cross-linking effect was not stable and the moisture resistance was poor. However, adding a small amount of distilled water, crosslinking agent would permeate into the resin in the help of distilled water; the thickness of surface cross-linking and moisture resistance were increased after heating treatment. Distilled water at different mass ratios $\left(\mathrm{H}_{2} \mathrm{O} / \mathrm{C}_{2} \mathrm{H}_{5} \mathrm{OH}=\right.$ $20 \%, 40 \%, 60 \%, 80 \%)$ was added in the mixture of $15 \%$ epoxy chloropropane and absolute ethanol, and the moisture resistance was tested. When the mass ratio of $\mathrm{H}_{2} \mathrm{O} / \mathrm{C}_{2} \mathrm{H}_{5} \mathrm{OH}$ reached $40 \%$, the SAP exhibited the best moisture resistance. If the amount of distilled water kept increasing, the resin would swell seriously, adhesion among the particles occurred, and the moisture resistance reduced. The high cross-linking density coat, which formed on the particle surface of the resin by epoxy chloropropane treatment, increased the strength and dispersity of the SAP. Combined with the dry surface of resin particles, the moisture resistance of resin was improved to certain extent. In conclusion, when the mass ratio of $\mathrm{ECH} / \mathrm{C}_{2} \mathrm{H}_{5} \mathrm{OH}$ reached $15 \%$ and $\mathrm{H}_{2} \mathrm{O} / \mathrm{C}_{2} \mathrm{H}_{5} \mathrm{OH}$ reached $40 \%$, the properties of the SAP were the best (Figure 12).

3.6.2. Effect of Diethylene Glycol (DEG) Dosages on the Properties of SAP. Figure 13 shows the spectrum of the SAP before and after DEG modification. The peak at $1114-1120 \mathrm{~cm}^{-1}$ is stretching vibration peak of the ether groups, which indicated that diethylene glycol was successfully grafted in SAP.

Effect of Diethylene Glycol Dosages on the Water Absorption Properties of SAP. Table 3 shows the results of the water absorption for the different diethylene glycol dosages. The

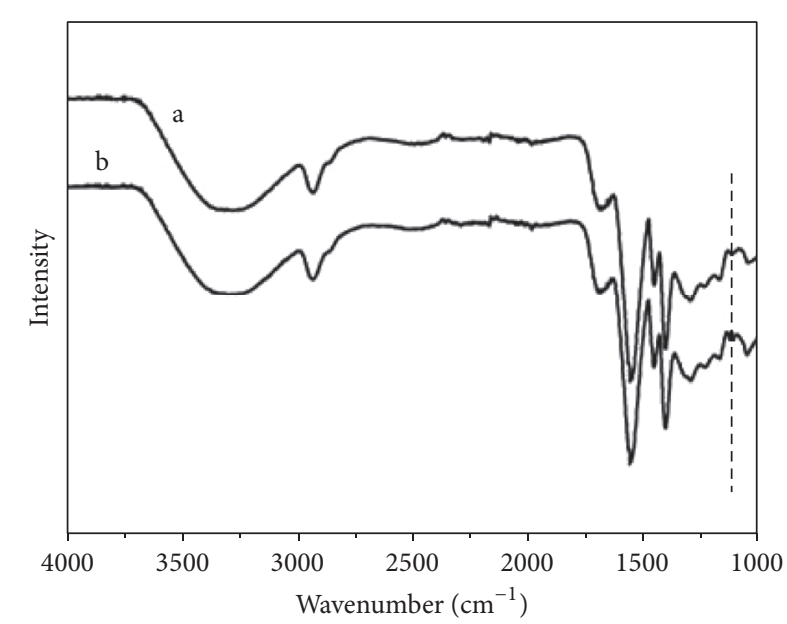

FIGURE 13: The IR comparison of the SAP before and after diethylene glycol modification (a: the IR of the SAP before DEG modification; b: the IR of the SAP modified by DEG).

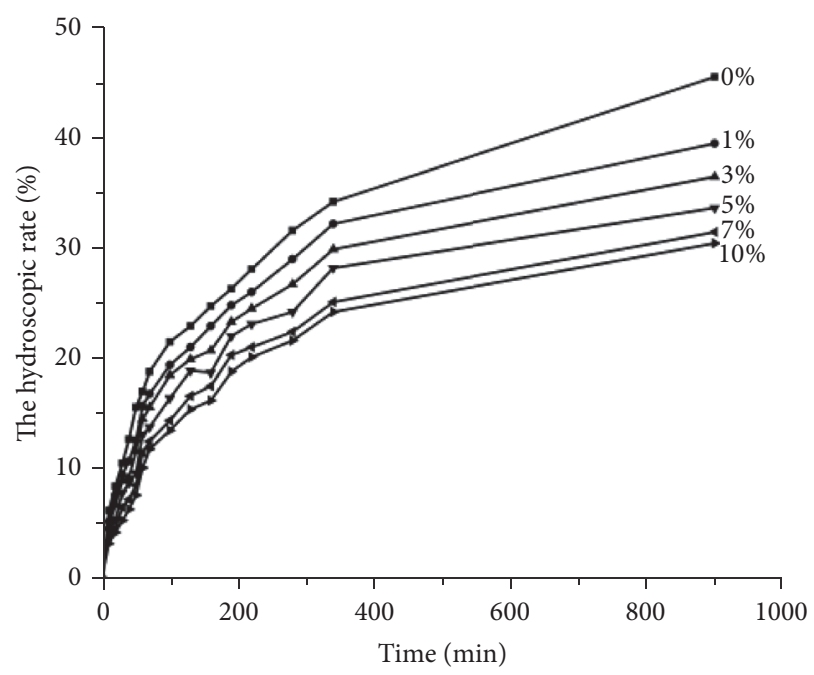

FIGURE 14: The moisture absorption rate of SAP with different dosage of diglycol modification.

water absorption was tested at different mass ratios of $\mathrm{ECH}$ and $\mathrm{C}_{2} \mathrm{H}_{5} \mathrm{OH}\left(\mathrm{ECH} / \mathrm{C}_{2} \mathrm{H}_{5} \mathrm{OH}=0 \%, 1 \%, 3 \%, 7 \%, 10 \%\right)$. Obviously, the amount of diethylene glycol dosage had a great effect on the water absorption. The results indicated that the particles in the resin bonded together performed with poor dispersivity when the mass ratio of $\mathrm{ECH} / \mathrm{C}_{2} \mathrm{H}_{5} \mathrm{OH}$ exceeded 10\% (Figure 14).

Effect of Diethylene Glycol Dosages on the Moisture Resistance of SAP. The resin was modified by the mixture of $2 \mathrm{~mL}$ distilled water, $5 \mathrm{~mL}$ anhydrous ethyl alcohol, and different amount of diethylene glycol. Results showed that the moisture resistance improved with the increasing of the amount 
TABLE 4: The optimum reaction conditions.

\begin{tabular}{lcccccc}
\hline $\begin{array}{l}\text { The cellulose } \\
\text { monomer } \\
\text { ratio }\end{array}$ & $\begin{array}{c}\text { Neutralization } \\
\text { degree }\end{array}$ & $\begin{array}{c}\text { Oil-water } \\
\text { ratio }\end{array}$ & $\begin{array}{c}\text { Reaction } \\
\text { temperature } \\
\left({ }^{\circ} \mathrm{C}\right)\end{array}$ & $\begin{array}{c}\text { The ratio of } \\
\mathrm{ECH} / \mathrm{C}_{2} \mathrm{H}_{5} \mathrm{OH}\end{array}$ & $\begin{array}{c}\text { The ratio of } \\
\mathrm{DEG} / \mathrm{C}_{2} \mathrm{H}_{5} \mathrm{OH}\end{array}$ & $\begin{array}{c}\text { Water absorption } \\
\text { rate }(\mathrm{g} / \mathrm{g})\end{array}$ \\
\hline $1: 10$ & $75 \%$ & $3: 1$ & 70 & $15 \%$ & $5 \%$ & $\begin{array}{c}\text { Salt water } \\
\text { absorption rate } \\
(\mathrm{g} / \mathrm{g})\end{array}$ \\
\hline
\end{tabular}

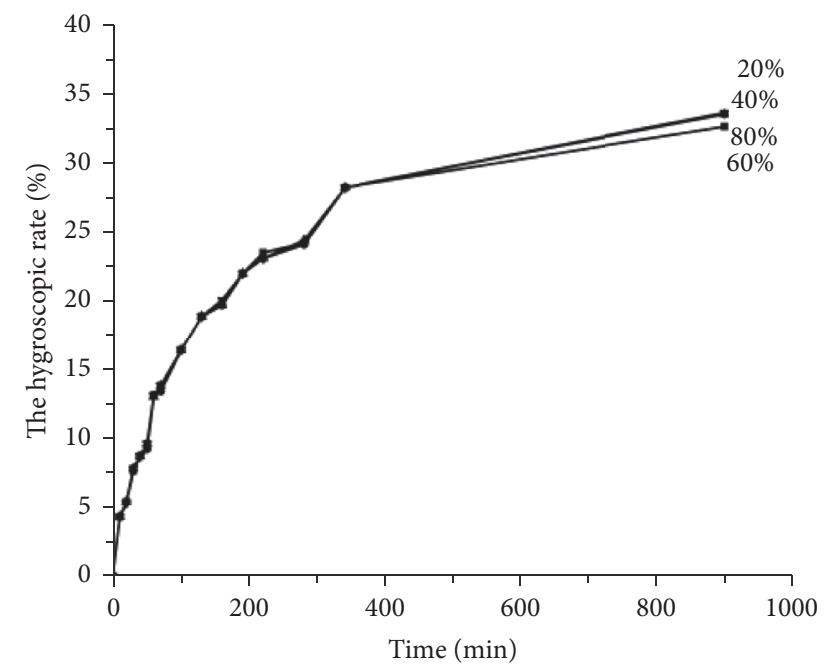

FIGURE 15: The moisture absorption rate of SAP with different dosage of distilled water.

of DEG. Compared with the resin treated by $\mathrm{ECH}$, the moisture resistance of the SAP treated by DEG exhibited better performance in spite of less gel strength and poorer dryness of resin surface. Once the amount of DEG was more than $7 \%$, the adhesion would happen among the particles of resin. And it was difficult to granulate after drying.

Effect of Distilled Water Quantity on the Moisture Performance of SAP. When distilled water at different mass ratios $\left(\mathrm{H}_{2} \mathrm{O} / \mathrm{C}_{2} \mathrm{H}_{5} \mathrm{OH}=20 \%, 40 \%, 60 \%, 80 \%\right)$ was added, the moisture resistance of the resin which was processed by $5 \%$ DEG was measured. The addition of distilled water had little influence on the treatment of DEG, in respect of the fact that the DEG is a hydrophilic agent with great property of penetrability; it can infiltrate easily without water (Figure 15).

The humidity resistance of the resin improved with the increasing amount of DEG. The water absorption efficiency reduced, and the impact was lower than the resin processed by ECH. When the amount of DEG exceeded $10 \%$, the particles among the resin adhered seriously. Although the moisture resistance of the resin treated by DEG was better than that treated by ECH, the gel strength and dispersity were inferior to it.

3.7. The Optimum Reaction Conditions. The optimum reaction conditions are as shown in Table 4.

\section{Conclusions}

In this study, the superabsorbent polymer has been synthesized through inverse suspension polymerization. The absorption experiments for water and salt water showed that the operating conditions such as monomer dosages, neutralization degree, oil-water ratio, temperature, and the cross-linking agent had great effects on the water absorption. The optimum reaction conditions were as follows: the cellulose monomer ratio: 1:10, neutralization degree: $75 \%$, oil-water ratio: $3: 1$, and reaction temperature: $70^{\circ} \mathrm{C}$. The water and salt water absorption rate can reach as high as $859 \mathrm{~g} / \mathrm{g}$ and $72.48 \mathrm{~g} / \mathrm{g}$, respectively. Moreover, the moisture resistance of the resin treated by ECH and DEG was improved significantly. The moisture resistance showed the best when the addition of $\mathrm{ECH}$ was $15 \%$, and it increased with the increasing amount of DEG, but when the dosage of DEG exceeded 5\%, the particles among the resin adhered seriously.

\section{Competing Interests}

The authors declare that they have no competing interests.

\section{Acknowledgments}

This work was supported by the Scientific Research Program of Hubei Provincial Department of Education (B2015321) and the Science Research Fund of Wuhan Institute of Technology.

\section{References}

[1] H. Kono and S. Fujita, "Biodegradable superabsorbent hydrogels derived from cellulose by esterification crosslinking with 1,2,3,4-butanetetracarboxylic dianhydride," Carbohydrate Polymers, vol. 87, no. 4, pp. 2582-2588, 2012.

[2] R. Ding and K. Gong, "Super-absorbent resin preparation utilizing spent mushroom substrates," Journal of Applied Polymer Science, vol. 130, no. 2, pp. 1098-1103, 2013.

[3] D. Wang, Z.-Q. Song, and S.-B. Shang, "Characterization and biodegradability of amphoteric superabsorbent polymers," Journal of Applied Polymer Science, vol. 107, no. 6, pp. 4116-4120, 2008.

[4] L. A. Gugliemelli, M. O. Weaver, and C. R. Russell, Salt-resistant thickeners comprising base-saponified starch-polyacrylonitrile graft copolymers: U.S. Patent 3,425,971[P]. 1969-2-4.

[5] K. Kabir, H. Mirzadeh, M. J. Zohuriaan-Mehr, and M. Daliri, "Chitosan-modified nanoclay-poly(AMPS) nanocomposite hydrogels with improved gel strength," Polymer International, vol. 58, no. 11, pp. 1252-1259, 2009.

[6] D. Shen, T. Wang, Y. Chen, M. Wang, and G. Jiang, "Effect of internal curing with super absorbent polymers on the relative humidity of early-age concrete," Construction and Building Materials, vol. 99, pp. 246-253, 2015.

[7] Y. G. Han, P. L. Yang, Y. P. Luo, S. M. Ren, L. X. Zhang, and L. Xu, "Porosity change model for watered super absorbent polymertreated soil," Environmental Earth Sciences, vol. 61, no. 6, pp. 1197-1205, 2010. 
[8] L. Zhou, Y. Wang, Z. Liu, and Q. Huang, "Characteristics of equilibrium, kinetics studies for adsorption of $\mathrm{Hg}(\mathrm{II}), \mathrm{Cu}(\mathrm{II})$, and $\mathrm{Ni}(\mathrm{II})$ ions by thiourea-modified magnetic chitosan microspheres," Journal of Hazardous Materials, vol. 161, no. 2-3, pp. 995-1002, 2009.

[9] C. Chang, B. Duan, J. Cai, and L. Zhang, "Superabsorbent hydrogels based on cellulose for smart swelling and controllable delivery," European Polymer Journal, vol. 46, no. 1, pp. 92-100, 2010.

[10] Y. Bulut, G. Akçay, D. Elma, and I. E. Serhatli, "Synthesis of claybased superabsorbent composite and its sorption capability," Journal of Hazardous Materials, vol. 171, no. 1-3, pp. 717-723, 2009.

[11] J. Zhang, L. Wang, and A. Wang, "Preparation and swelling behavior of fast-swelling superabsorbent hydrogels based on starch-g-poly(acrylic acid-co-sodium acrylate)," Macromolecular Materials and Engineering, vol. 291, no. 6, pp. 612-620, 2006.

[12] S. Changchaivong and S. Khaodhiar, "Adsorption of naphthalene and phenanthrene on dodecylpyridinium-modified bentonite," Applied Clay Science, vol. 43, no. 3, pp. 317-321, 2009.

[13] G. R. Mahdavinia, A. Pourjavadi, and M. J. Zohuriaan-Mehr, "A convenient one-step preparation of chitosan-poly(sodium acrylate-co-acrylamide) hydrogel hybrids with super-swelling properties," Journal of Applied Polymer Science, vol. 99, no. 4, pp. 1615-1619, 2006.

[14] Y. Zhou, S. Fu, L. Zhang, and H. Zhan, "Superabsorbent nanocomposite hydrogels made of carboxylated cellulose nanofibrils and CMC-g-p(AA-co-AM)," Carbohydrate Polymers, vol. 97, no. 2, pp. 429-435, 2013.

[15] H. A. Essawy, M. B. M. Ghazy, F. A. El-Hai, and M. F. Mohamed, "Superabsorbent hydrogels via graft polymerization of acrylic acid from chitosan-cellulose hybrid and their potential in controlled release of soil nutrients," International Journal of Biological Macromolecules, vol. 89, pp. 144-151, 2016.

[16] T. Fekete, J. Borsa, E. Takács, and L. Wojnárovits, "Synthesis of cellulose-based superabsorbent hydrogels by high-energy irradiation in the presence of crosslinking agent," Radiation Physics and Chemistry, vol. 118, pp. 114-119, 2014.

[17] F. F. Montesano, A. Parente, P. Santamaria, A. Sannino, and F. Serio, "Biodegradable superabsorbent hydrogel increaseswater retention properties of growing media and plant growth," Agriculture and Agricultural Science Procedia, vol. 4, pp. 451458, 2015.

[18] S. Mohammadi-Khoo, P. N. Moghadam, A. R. Fareghi, and N. Movagharnezhad, "Synthesis of a cellulose-based hydrogel network: characterization and study of urea fertilizer slow release," Journal of Applied Polymer Science, vol. 133, no. 5, Article ID 42935, 2016.

[19] M. Bakass, J. P. Bellat, A. Mokhlisse, and G. Bertrand, "The adsorption of water vapor on super absorbent product at low temperatures and low mass," Journal of Applied Polymer Science, vol. 100, no. 2, pp. 1450-1456, 2006.

[20] Y. Zhang, H. Wang, C. Gao, X. Li, and L. Li, "Highly ordered mesoporous carbon nanomatrix as a new approach to improve the oral absorption of the water-insoluble drug, simvastatin," European Journal of Pharmaceutical Sciences, vol. 49, no. 5, pp. 864-872, 2013.

[21] J. Slane, J. Vivanco, J. Meyer, H.-L. Ploeg, and M. Squire, "Modification of acrylic bone cement with mesoporous silica nanoparticles: effects on mechanical, fatigue and absorption properties," Journal of the Mechanical Behavior of Biomedical Materials, vol. 29, pp. 451-461, 2014.
[22] J. E. Mathis, Z. Bi, C. A. Bridges et al., "Enhanced visible-light absorption of mesoporous $\mathrm{TiO}_{2}$ by co-doping with transitionmetal/nitrogen ions," in MRS Online Proceeding Library Archive, vol. 1547 of MRS Proceedings, pp. 115-119, Cambridge University Press, January 2013.

[23] D. Sun, W. Jiang, Y. Wang et al., "Synthesis and enhanced electromagnetic wave absorption properties of $\mathrm{Fe}_{3} \mathrm{O}_{4} @ \mathrm{ZnO}$ mesoporous spheres," MRS Proceedings, vol. 1663, 2014.

[24] W. Cui, Y. Li, Y. Ma, and G. Yu, "Research on the dehydration property of one of super absorbent resin on the swill oil," Modern Applied Science, vol. 4, no. 10, article no. 71, 2010.

[25] H. Ye, J.-Q. Zhao, and Y.-H. Zhang, "Novel degradable superabsorbent materials of silicate/acrylic-based polymer hybrids," Journal of Applied Polymer Science, vol. 91, no. 2, pp. 936-940, 2004. 

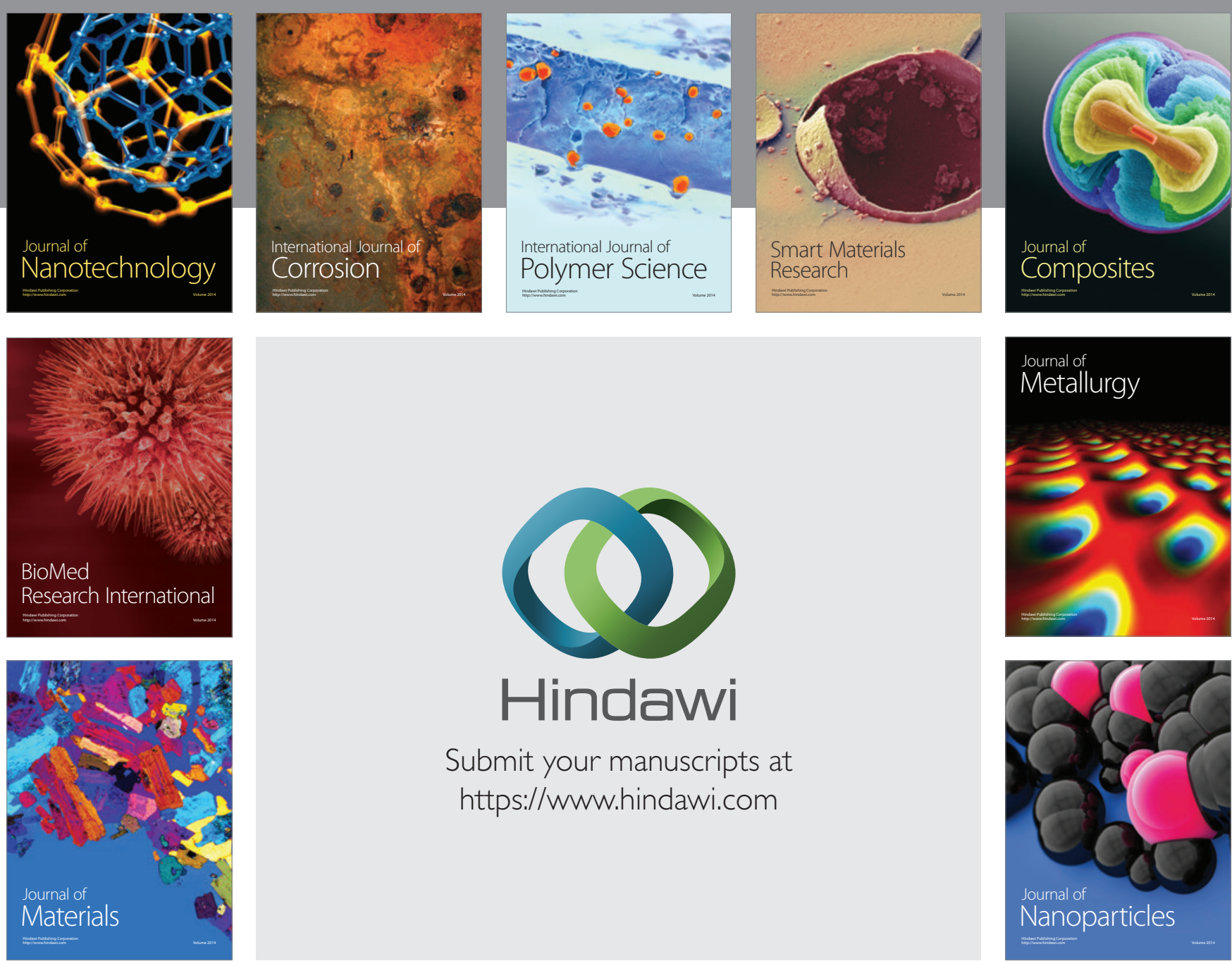

\section{Hindawi}

Submit your manuscripts at

https://www.hindawi.com

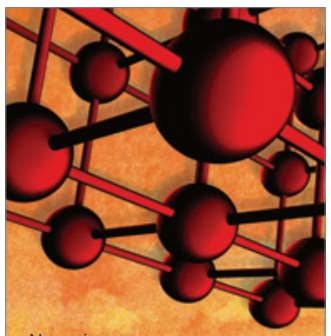

Materials Science and Engineering
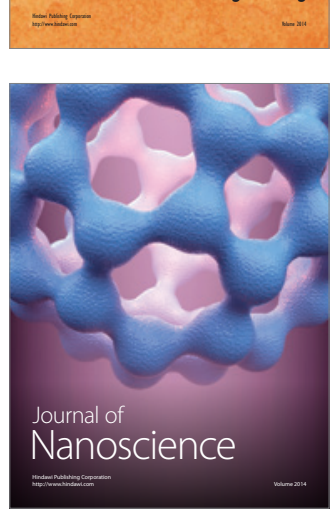
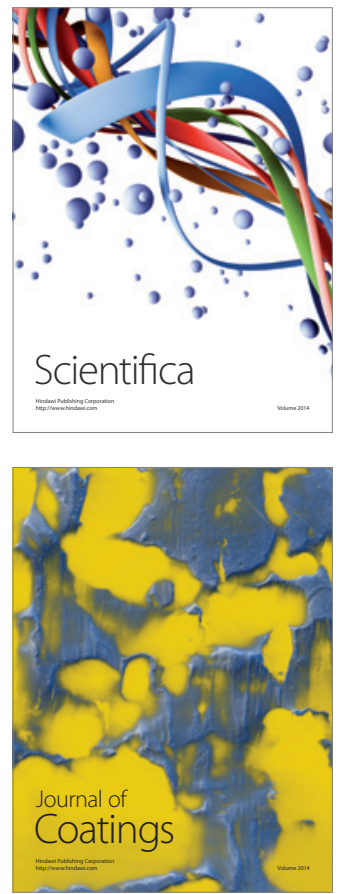
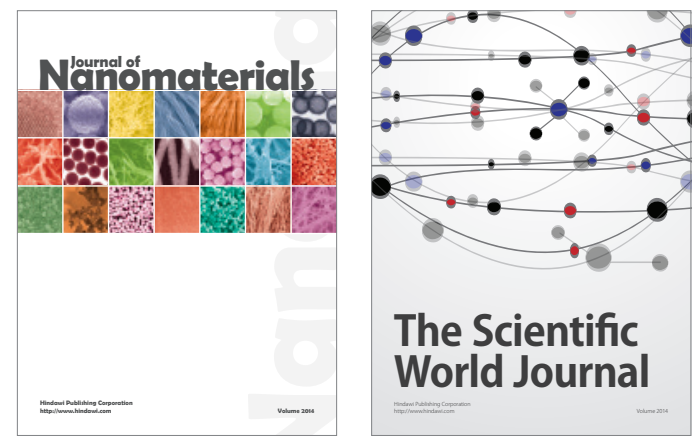

The Scientific World Journal
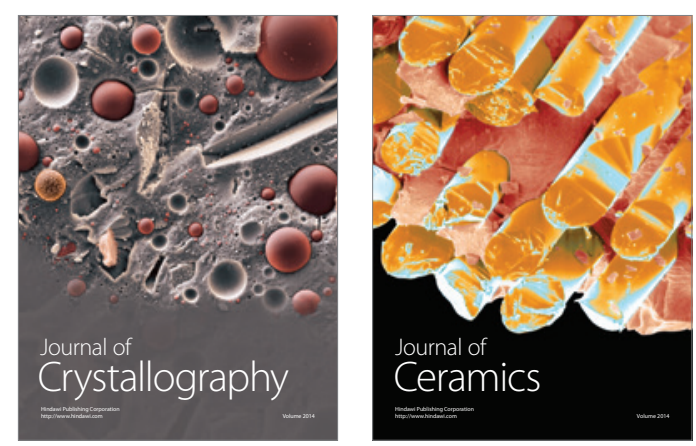
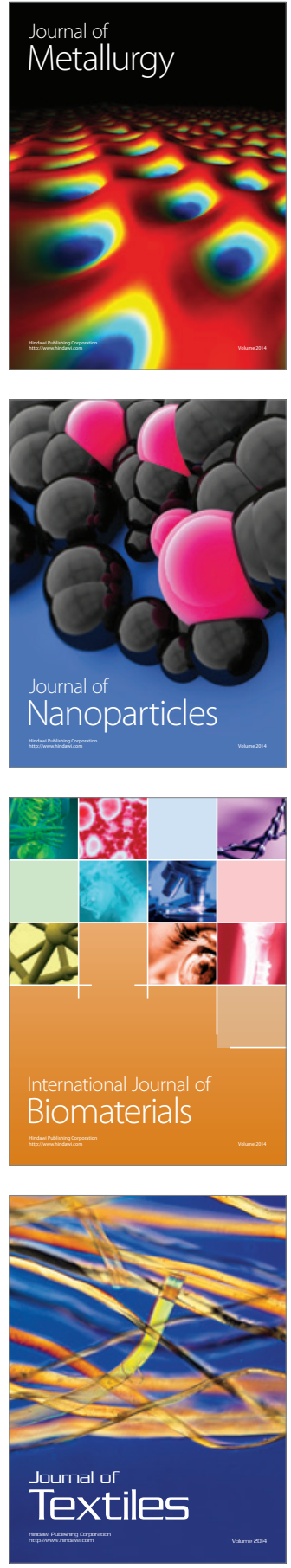